\title{
Effect of Crop Root on Soil Water Retentivity and Movement
}

\author{
Kozue Yuge $^{1 *}$, Keiki Shigematsu ${ }^{2},{\text { Mitsumasa } \text { Anan }^{3} \text {, Shinogi Yoshiyuki }}^{1}$ \\ ${ }^{1}$ Faculty of Agriculture, Kyushu University, Fukuoka, Japan; ${ }^{2}$ Graduate School of Bioresource and Bioenvironment Science, Kyushu \\ University, Fukuoka, Japan; ${ }^{3}$ Takasaki Sogo Consultant Co., Ltd., Kurume, Japan. \\ Email: *yuge@bpes.kyushu-u.ac.jp
}

Received September $13^{\text {th }}, 2012$; revised October $18^{\text {th }}, 2012$; accepted November $14^{\text {th }}, 2012$

\begin{abstract}
The objective of this study was to clarify the effect of crop root on soil water retentivity and movement to improve the crop growth environment and irrigation efficiency. To simulate soil water movement considering the crop root effect on the physical properties of soil, a numerical model describing the soil water and heat transfers was introduced. Cultivation experiments were conducted to clarify the effect of the crop root on soil water retentivity and verify the accuracy of the numerical model. The relationship between soil water retentivity and the root content of soil samples was clarified by soil water retention curves. The soil water content displayed a high value with increasing crop root content in the high volumetric water content zone. The experimental results indicated that the saturated water content increased with the crop root content because of the porosity formed by the crop root. The differences of the soil water retentivity became smaller when the value of the matric potential was over $\mathrm{pF} 1.5$. To verify the accuracy of the numerical model, an observation using acrylic slit pot was also conduced. The temporal and spatial changes of the volumetric water content and soil temperature were measured. Soil water and heat transfers, which considered the effect of the crop root on the soil water retentivity clarified by the soil water retention curves, were simulated. Simulated volumetric water content and temperature of soil agreed with observed data. This indicated that the numerical model used to simulate the soil water and heat transfer considering the crop root effect on soil water retentivity was satisfactory. Using this model, spatial and temporal changes of soil water content were simulated. The soil water condition of the root zone was relatively high compared with the initial conditions. This indicated that the volumetric water condition of the root zone increased with the soil water extraction and high soil water conditions was maintained because the soil water retentivity of root zone increased with the root effect.
\end{abstract}

Keywords: Water Consumption; Soil Water; Heat Transfer; Numerical Model; Irrigation Water Saving

\section{Introduction}

Irrigation scheduling is one of the most important factors for healthy breeding of crops. Quantification of water consumption is necessary for both adequate crop breeding and improved irrigation efficiency. Mechanism of water consumption and soil water movement is affected by crop roots because the soil structure and physical properties are changed by crop root physiological activities, including growth or water extraction. To quantify the water consumption in crop fields, the crop root effects on soil physical properties should be clarified.

Various researches have been conducted to clarify the biochemical and physical effects of soil on crop root growth. Drew (1975) [1] studied the adequate external concentrations of nitrogen and phosphorus required by root growth. Effects of various chemical materials of soil

\footnotetext{
"Corresponding author.
}

on crop root growth have been clarified [2-9]. Iijima et al. (1991) [10] determined the effects of soil compaction on the development of root system components of rice and maize. A combined root growth and water extraction model was introduced by Bengough (1997) [11]. Crop root cellular response to soil physical stress was evaluated by Bengough et al. (2006) [12]. Effects of the soil water content and bulk density on crop root development processes were investigated by Becel et al. (2012) [13].

Although the effects of soil biochemical and physical conditions on crop root growth have been extensively studied, the effects of the crop root on the physical properties and water consumption of soil have not been clarified.

Studies have been conducted to clarify soil water movement and quantify water consumption in the crop fields $[14,15]$. However, the crop root effect on the physical properties of soil was not considered in these 
studies, as a method to evaluate soil water movement considering the effect of the crop root on the soil physic properties has not been established.

The objective of this study is to clarify the effects of the crop root on soil water retentivity and soil water movement. A numerical model was introduced to simulate the soil water and heat transfer considering the crop root effect on soil water retentivity. Cultivation experiments were conducted to clarify the relationship between soil water retentivity and crop root content and to verify the accuracy of the numerical model.

\section{Methodology}

\subsection{Governing Equations of Soil Water and Heat Transfer}

To estimate the soil water transport considering the crop root effect on soil water retentivity and hydraulic conductivity, a numerical model was introduced. The governing equation describing soil water and heat transfers can be described as follows:

$$
\begin{aligned}
\frac{\partial \theta}{\partial t}= & \frac{\partial}{\partial x}\left(D_{w} \frac{\partial \theta}{\partial x}\right)+\frac{\partial}{\partial z}\left(D_{w} \frac{\partial \theta}{\partial z}\right) \\
& +\frac{\partial}{\partial x}\left(D_{T} \frac{\partial T}{\partial x}\right)+\frac{\partial}{\partial z}\left(D_{T} \frac{\partial T}{\partial z}\right)+\frac{\partial K}{\partial x}+S \\
C_{v} \frac{\partial T}{\partial t} & =\frac{\partial}{\partial x}\left(\lambda \frac{\partial T}{\partial x}\right)+\frac{\partial}{\partial z}\left(\lambda \frac{\partial T}{\partial z}\right) \\
& +L \rho_{l}\left\{\frac{\partial}{\partial x}\left(D_{w v} \frac{\partial \theta}{\partial x}\right)+\frac{\partial}{\partial z}\left(D_{w v} \frac{\partial \theta}{\partial z}\right)\right\}
\end{aligned}
$$

where $C_{v}$ is the volumetric heat capacity $\left(\mathrm{J} \cdot \mathrm{m}^{-3} \cdot{ }^{\circ} \mathrm{C}^{-1}\right), D_{\theta}$ is the isothermal water diffusivity $\left(\mathrm{m}^{2} \cdot \mathrm{s}^{-1}\right), D_{\theta v}$ is the isothermal vapor diffusivity $\left(\mathrm{m}^{2} \cdot \mathrm{s}^{-1}\right), D_{T}$ is the thermal water diffusivity $\left(\mathrm{m}^{2} \cdot \mathrm{s}^{-1} \cdot{ }^{\circ} \mathrm{C}^{-1}\right), K$ is the hydraulic conductivity $\left(\mathrm{m} \cdot \mathrm{s}^{-1}\right), L$ is the latent heat of water vaporization $\left(\mathrm{J} \cdot \mathrm{kg}^{-1}\right)$, $S$ is the $\operatorname{sink}\left(\mathrm{m}^{3} \cdot \mathrm{m}^{-3} \cdot \mathrm{s}^{-1}\right), T$ is the soil temperature $\left({ }^{\circ} \mathrm{C}\right), t$ is the time $(\mathrm{s}), \lambda$ is the thermal conductivity $\left(\mathrm{W} \cdot \mathrm{m}^{-1} \cdot{ }^{\circ} \mathrm{C}^{-1}\right)$, $\rho_{l}$ is the water density $\left(\mathrm{kg} \cdot \mathrm{m}^{-3}\right)$, and $\theta$ is the volumetric soil water content $\left(\mathrm{m}^{3} \cdot \mathrm{m}^{-3}\right)$.

\subsection{Boundary Conditions}

The energy budget on the soil surface at the crop field can be described as follows:

$$
R_{n}=E+H+G
$$

where $R_{n}$ is the net radiation $\left(\mathrm{W} \cdot \mathrm{m}^{-2}\right), E$ is the latent heat flux $\left(\mathrm{W} \cdot \mathrm{m}^{-2}\right), H$ is the sensible heat flux $\left(\mathrm{W} \cdot \mathrm{m}^{-2}\right)$, and $G$ is the ground heat flux $\left(\mathrm{W} \cdot \mathrm{m}^{-2}\right)$.

The net radiation $R_{n}$ can be estimated using the following equation considering the shortwave and longwave radiation balance.

$$
R_{n}=(1-\alpha) R_{s}+L_{c}+L_{\text {sky }}-L_{\text {soil }}
$$

where $R_{s}$ is the shortwave radiation on the soil surface $\left(\mathrm{W} \cdot \mathrm{m}^{-2}\right), L_{c}$ is the longwave radiation from the crop body $\left(\mathrm{W} \cdot \mathrm{m}^{-2}\right), L_{\text {sky }}$ is the longwave radiation from the sky $\left(\mathrm{W} \cdot \mathrm{m}^{-2}\right.$ ), and $L_{\text {soil }}$ is the longwave radiation from the soil surface $\left(\mathrm{W} \cdot \mathrm{m}^{-2}\right)$.

The sensible heat flux and the latent heat flux on the soil surface can be estimated as follows

$$
\begin{aligned}
& H=c_{p} \rho \frac{T_{s}-T_{a}}{r} \\
& L E=\frac{c_{p} \rho}{\gamma} \frac{e_{s}-e_{a}}{r}
\end{aligned}
$$

where $T_{s}$ is the soil surface temperature $\left({ }^{\circ} \mathrm{C}\right), c_{p}$ is the specific heat of the air $\left(\mathrm{J} \cdot \mathrm{kg}^{-1} \cdot{ }^{\circ} \mathrm{C}^{-1}\right), e_{a}$ is the air vapor pressure $(\mathrm{hPa}), e_{s}$ is the vapor pressure on the soil surface $(\mathrm{hPa}), r_{a}$ is the diffusion resistance $\left(\mathrm{s} \cdot \mathrm{m}^{-1}\right), \alpha$ is the albedo, $\gamma$ is the psychrometer constant $\left(\mathrm{hPa} \cdot{ }^{\circ} \mathrm{C}^{-1}\right)$, and $\rho_{a}$ is the air density $\left(\mathrm{kg} \cdot \mathrm{m}^{-3}\right)$.

The diffusion resistance can be calculated using the following equation (Chamberlain, 1968):

$$
r_{a}=\frac{1}{\kappa u_{*}} \ln \left(\frac{z}{z_{0}}\right)+a\left(\frac{u_{*} \xi}{v}\right)^{b}\left(\frac{v}{D_{v}}\right)^{c}
$$

where $D_{v}$ is the molecular diffusion coefficient $\left(\mathrm{m}^{2} \cdot \mathrm{s}^{-1}\right)$, $u *$ is the friction velocity $\left(\mathrm{m} \cdot \mathrm{s}^{-1}\right), z$ is the height of the measurement of the wind velocity $(\mathrm{m}), z_{0}$ is the roughness length $(\mathrm{m}), \xi$ is the effective soil surface roughness $(\mathrm{m})$, and $v$ is the kinematic viscosity of air $\left(\mathrm{m}^{2} \cdot \mathrm{s}^{-1}\right)$. The constants $a, b$, and $c$ are reported as $0.52,0.45$, and 0.8 , respectively, by Chamberlain (1968) [16].

Using energy balance estimated by Equations (3)-(7), boundary conditions on the soil surface can be described as follows:

$$
\begin{gathered}
E=L \rho_{w}\left(-D_{w} \frac{\partial \theta}{\partial z}-D_{T} \frac{\partial T}{\partial z}-K\right) \\
G=-\lambda \frac{\partial T}{\partial z}-L \rho_{w} D_{w v} \frac{\partial \theta}{\partial z}
\end{gathered}
$$

\subsection{Model Structure}

Figure 1 shows the numerical model describing water and heat transfers in the soil. To solve the two-dimensional transfers of water and heat, the finite-differential method was used. As the bottom boundary condition, the soil water potential was set as constant. The matric potential and hydraulic conductivity were set considering the root content for an interior node. The sink was set using the transpiration rate.

\section{Cultivation Experiments}

A cultivation experiment was conducted to evaluate the 


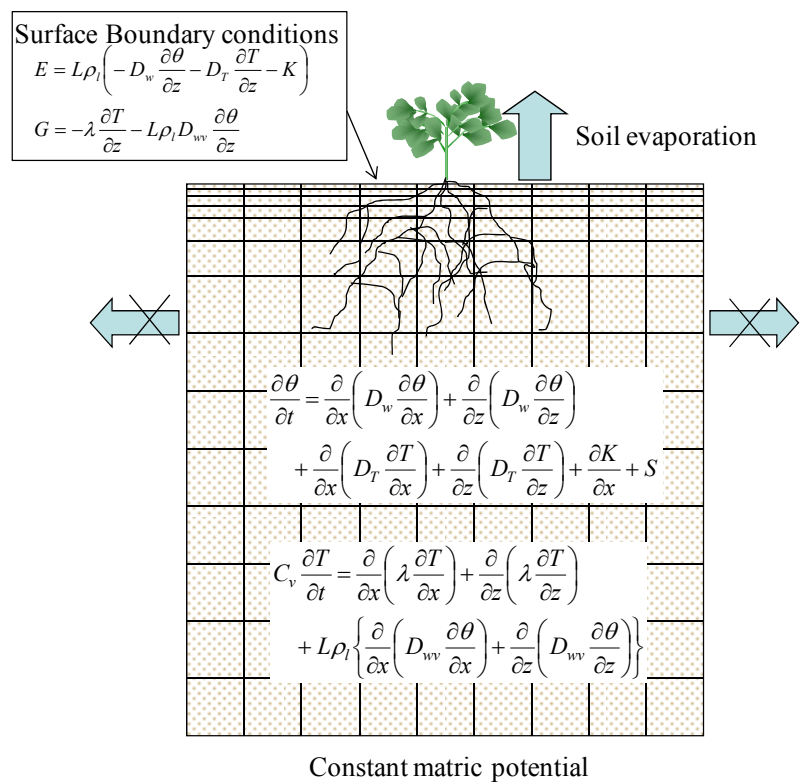

Figure 1. Schematic view of the numerical model describing the water and heat transfers in soil.

effect of the crop root on soil water retentivity. The soil containing the crop root was sampled. Soil moisture characteristic curves were estimated, and the volumetric root contents of soil samples were measured to clarify the relationship between the soil water retentivity and root contents.

To verify the numerical model accuracy, an observation using acrylic slit pot was also conduced. Figure 2 shows the condition of the experiment. Broccoli was planted in the acrylic slit pot, at a size of $0.5 \mathrm{~m} \times 0.6 \mathrm{~m} \times$ $0.1 \mathrm{~m}$. The ballasts were paved at the bottom of the acrylic slit pot, and the weathered granite soil was filled at a depth of $0.48 \mathrm{~m}$. The volumetric water content and soil temperature were measured by soil moisture sensors (SM200, Delta-T) and thermo-couples at the depths shown in Figure 3. The solar radiations on the soil surface were measured by pyranometers (LI-200, LI-COR) to calculate the net radiation by Equation (4). In addition, the air temperature and humidity were measured to estimate the sensible and latent heat fluxes by Equations (5) and (6). The crop root content in $5 \mathrm{~cm} \times 5 \mathrm{~cm}$ soil portion was measured by imaging analysis using the cross-sectional photograph taken from the front side of the acrylic slit pot.

\section{Results and Discussion}

\subsection{Relationship between Soil Water Retentivity and Root Content}

Figure 4 shows the relationship between the soil water retention curves and the crop root content in the soil sample. This figure indicates that the soil water retentive-

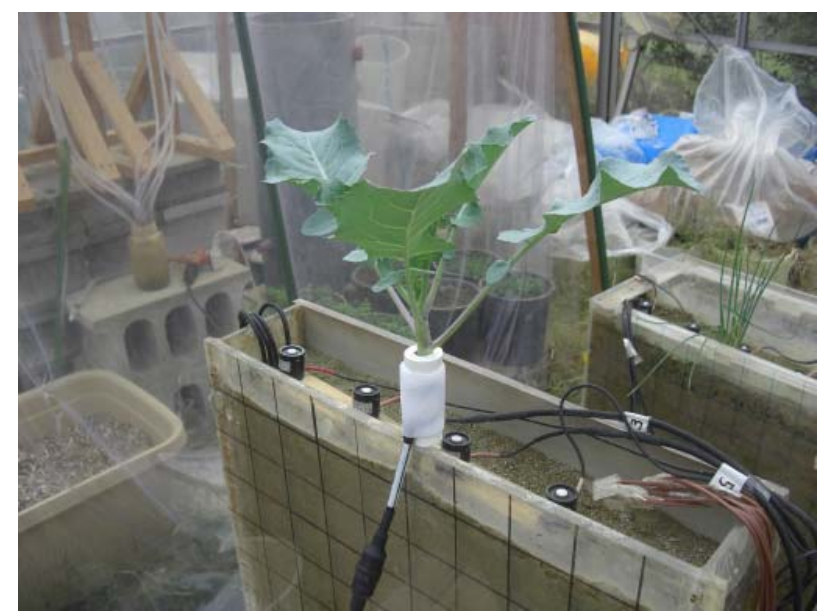

Figure 2. Condition of the cultivation experiment to verify model accuracy.

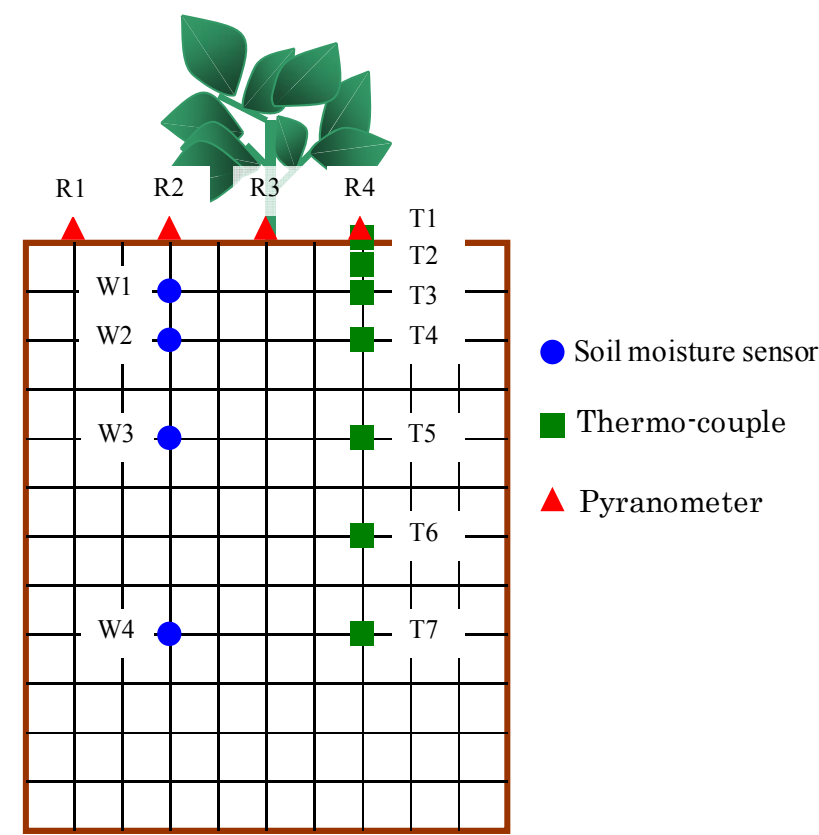

Figure 3. Schematic view of the observation.

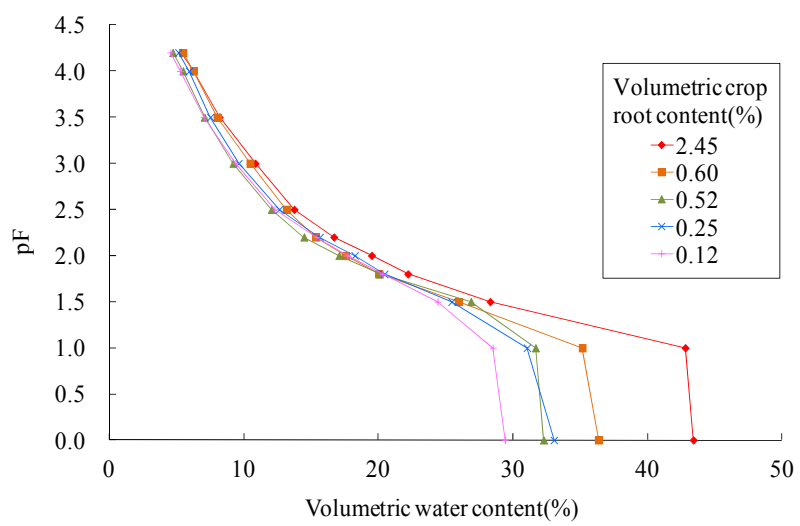

Figure 4. Relationship between the soil water retention curves and crop root content. 
ity varied with the root content of the soil sample. In the high volumetric water content zone, the soil water content showed a high value with increasing root content. The experimental results indicate that the saturated water content increased with the crop root content because of the porosity generated by the crop root. The differences of the soil water retentivity became smaller when the matric potential was over $\mathrm{pF} 1.5$.

\subsection{Model Accuracy}

Using the numerical model described in Figure 1, the soil water movement was estimated. Figure $\mathbf{5}$ shows the distribution of root content measured by the cultivation experiment. Using these data, the matric potential for interior nodes was given using the soil water retention curves considering the root content in the simulation procedure.

Figure 6 shows the comparison of simulated and observed volumetric water contents at depths of $5 \mathrm{~cm}$ and $20 \mathrm{~cm}$. Simulated values agree with the observed data. As the soil moisture movement was minimal in this period, the model accuracy was also verified using soil temperature. Figure 7 shows the simulated and observed soil temperature at depths of $0 \mathrm{~cm}$ and $5 \mathrm{~cm}$. The tendency of the simulated soil temperature were consistent with the observed data. This indicates that the numerical model to simulate the soil water and heat transfer considering the crop effect on soil water retentivity is satisfactory.

\subsection{Spatial Distribution and Temporal Change of Volumetric Water Content}

Using the numerical model, temporal and spatial changes of soil water condition were estimated. Figure 8 shows the spatial distribution of volumetric water content of soil

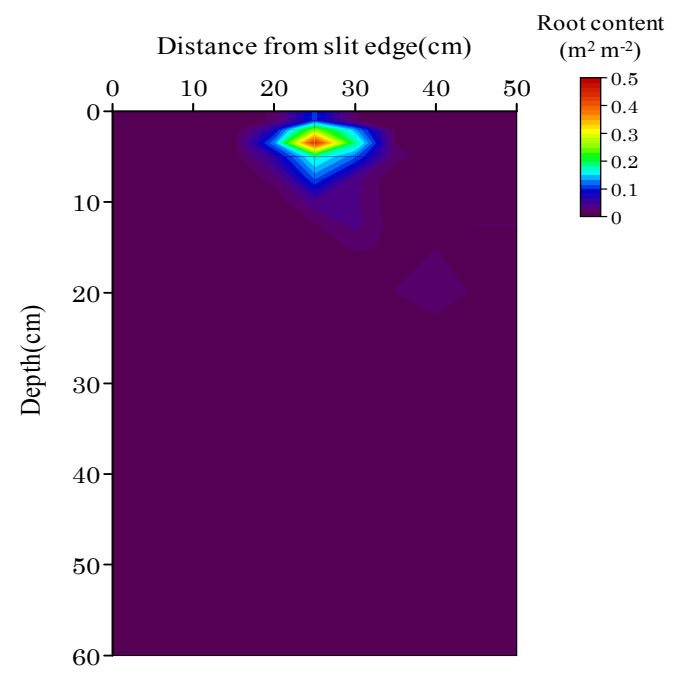

Figure 5. Spatial distribution of the crop root content.

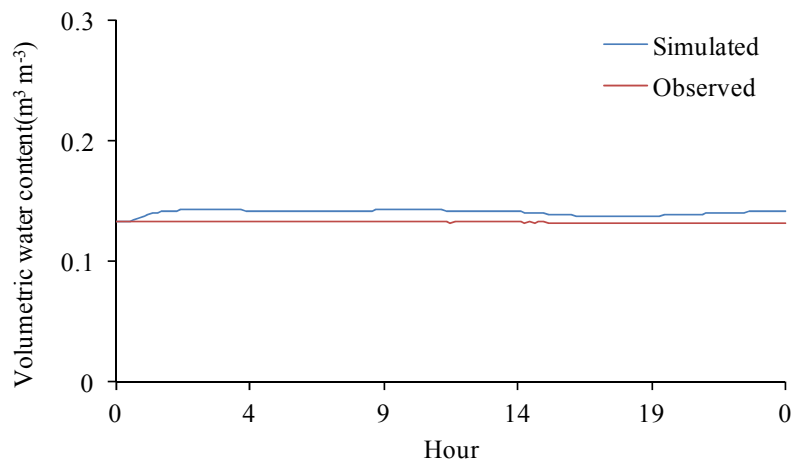

(a) $5 \mathrm{~cm}$

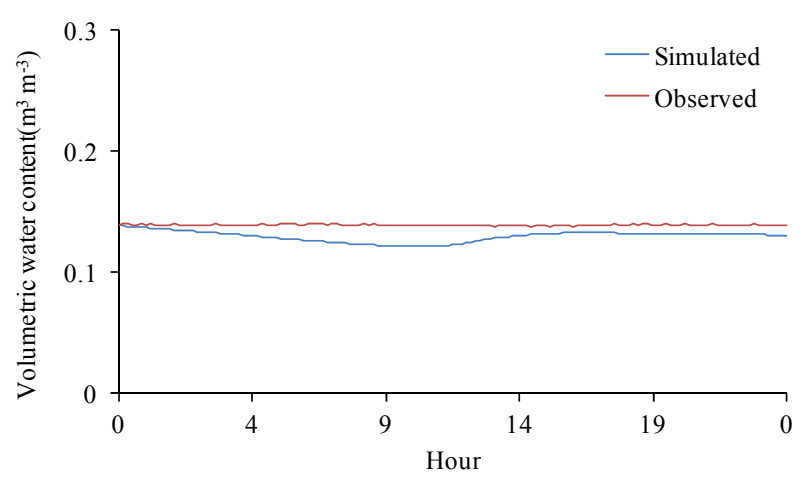

(b) $20 \mathrm{~cm}$

Figure 6. Comparison of simulated and observed volumetric water contents.

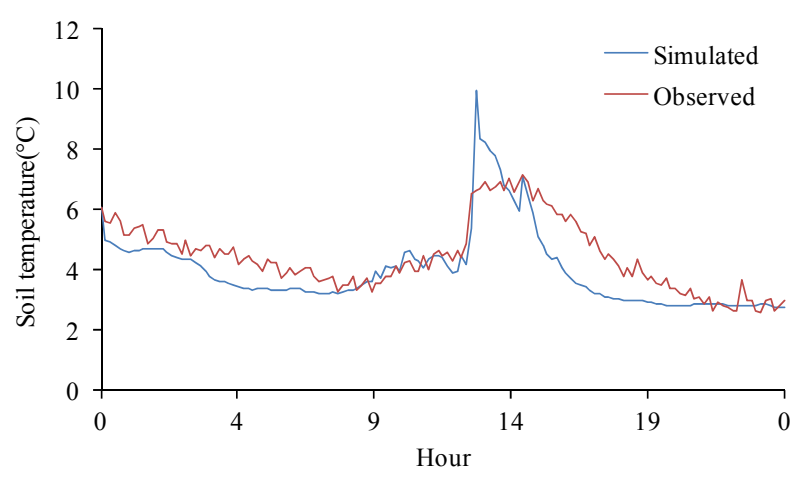

(a) $0 \mathrm{~cm}$

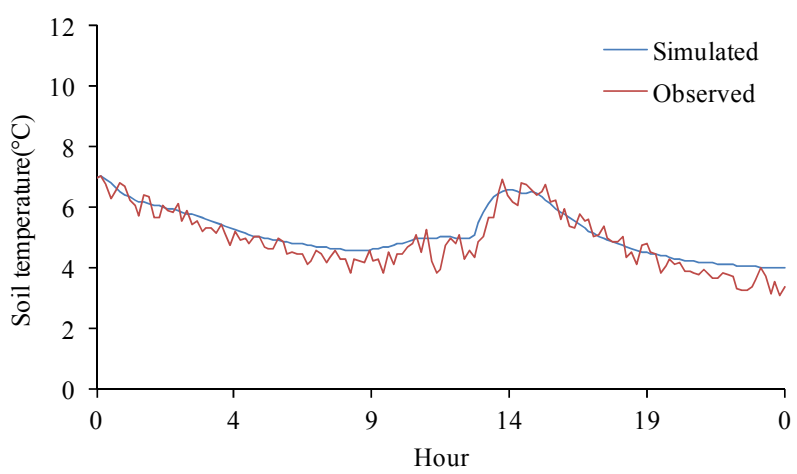

(b) $5 \mathrm{~cm}$

Figure 7. Comparison of simulated and observed soil temperature. 


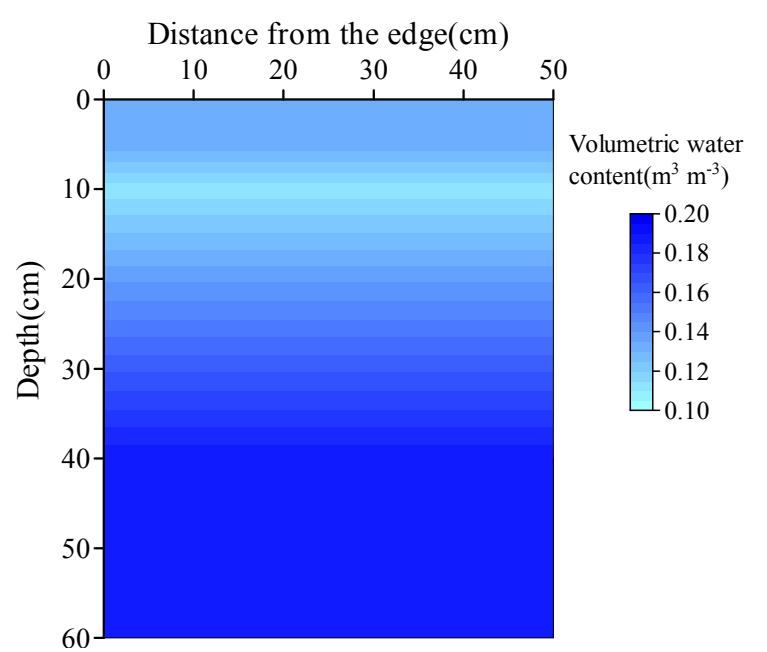

(a) 0:00

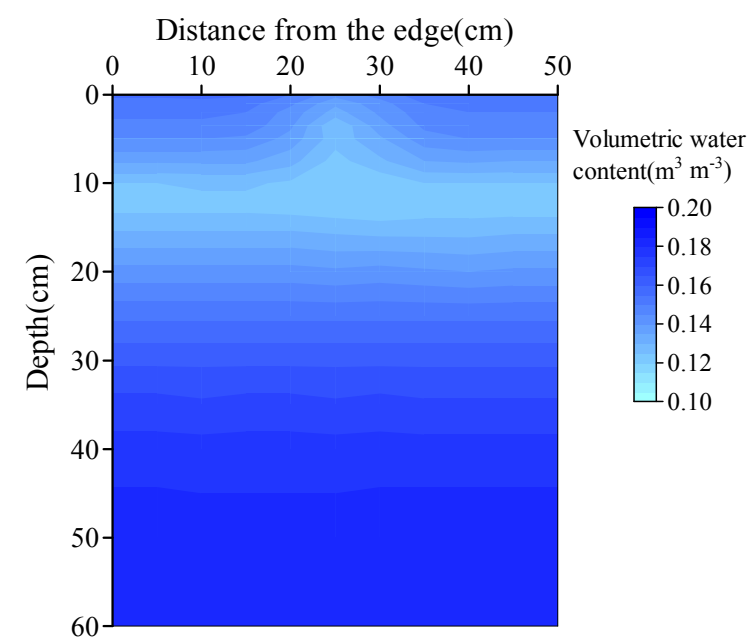

(c) $14: 00$

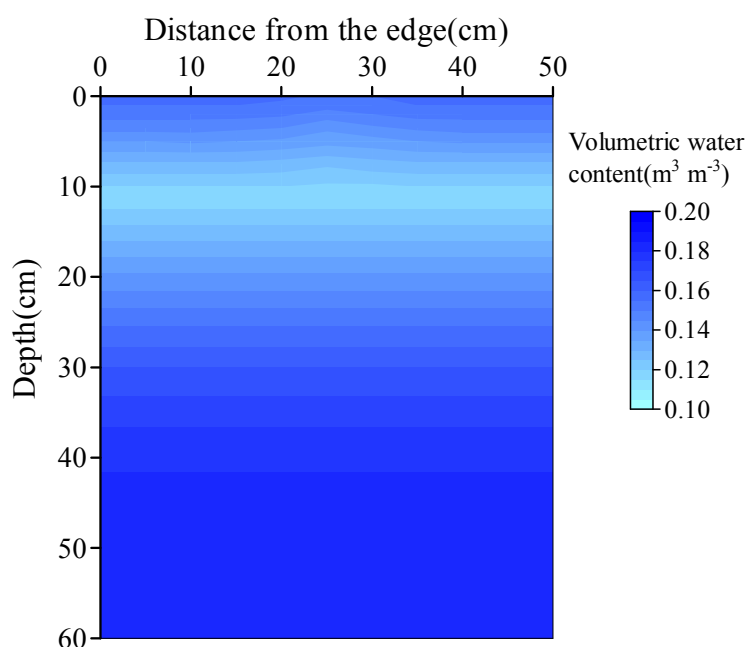

(b) 10:00

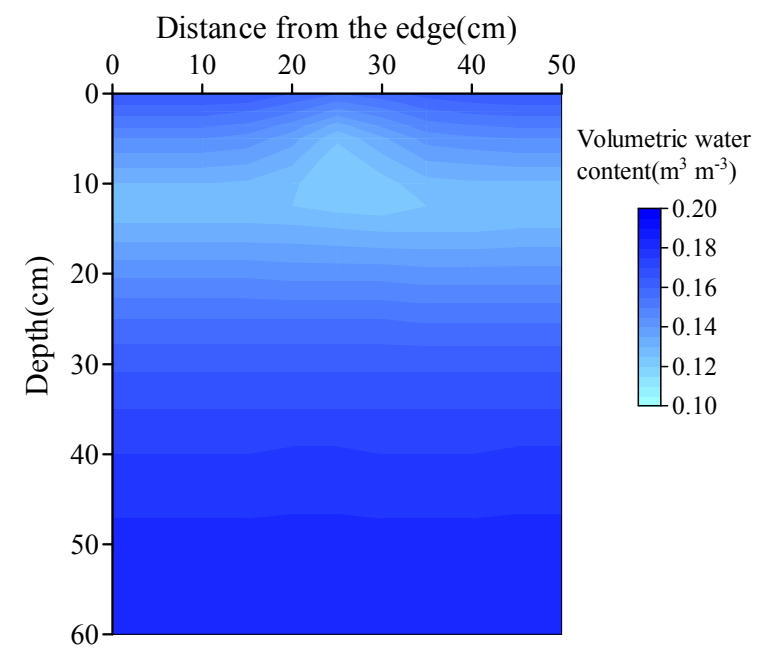

(d) 18:00

Figure 8. Comparison of simulated and observed soil temperature(continued).

every four hours. The distribution of the volumetric water content around root zone changed from 10 a.m. because of the soil water extraction by the crop root. The soil water condition of root zone was relatively high compared with the initial condition shown in Figure 8(a). This result indicates that the volumetric water condition of root zone increased with the soil water extraction, and high soil water condition was maintained because the soil water retentivity of root zone increased with the root content.

\section{Conclusion}

To simulate soil water movement considering the crop root effect on soil water retentivity, a numerical model describing soil water and heat transfers was introduced. Cultivation experiments were conducted to clarify the effect of crop roots on soil water retentivity and to verify the accuracy of the numerical model. The relationship between soil water retentivity and root content was clarified by soil water retention curves. The soil water content was directly related to root content in the high volumetric water content zone. The differences in soil water retentivity decreased when the matric potential was over $\mathrm{pF}$ 1.5. Simulated volumetric water content and temperature of soil agreed with observed data. Using this model, spatial and temporal changes of soil water content were simulated. The soil water condition of the root zone was relatively high compared with initial conditions. This result indicates that the volumetric water condition of the root zone increased with soil water extraction, and high soil water condition was maintained because the soil water retentivity of root zone increased with the root content. The method introduced here is effective to estimate more accurately water consumption in crop fields. Considering the crop root effect on soil water conditions will allow scientists and farmers to correctly irrigate for crop growth and save irrigation water. 


\section{REFERENCES}

[1] M. C. Drew, "Comparison of Effects of a Localized Supply of Phosphate, Nitrate, Ammonium and Potassium on Growth of Seminal Root System, and Shoot, in Barley," New Phytologist, Vol. 75, No. 3, 1975, pp. 479-490. doi:10.1111/j.1469-8137.1975.tb01409.x

[2] I. J. Bingham and E. A. Stevenson, "Control of RootGrowth-Effects of Carbohydrates on the Extension, Branching and Rate of Respiration of Different Fractiations of Wheat Roots," Physiologia Plantarum, Vol. 88, No. 1, 1993, pp. 149-158.

[3] A. E. S. Macklon, L. A. Mackiedawson, A. Sim, C. A. Shand and A. Lilly, "Soil-P Resources, Plant-Growth and Rooting Characteristics in Nutrient Poor Upland Grasslands," Plant and Soil, Vol. 163, No. 2, 1994, pp. 257266. doi: 10.1007/BF00007975

[4] V. M. Dunbabin, A. J. Diggle, Z. Rengel and R. van Hugten, "Modelling the Interactions between Water and Nutrient Uptake and Root Growth," Plant and Soil, Vol. 239, No. 1, 2002, pp. 19-38. doi:10.1023/A:1014939512104

[5] M. J. Hutchings and E. A. John, "The Effects of Environmental Heterogeneity on Root Growth and Root/Shoot Partitioning," Annals of Botany, Vol. 94, No. 1, 2004, pp. 1-8. doi:10.1093/aob/mch111

[6] Q. Y. Tian, F. J. Chen, J. X. Liu, F. S. Zhang and G. H. Mi, "Inhibition of Maize Root Growth by High Nitrate Supply Is Correlated with Reduced IAA Levels in Roots," Journal of Plant Physiology, Vol. 165, No. 9, 2008, pp. 942-951. doi:10.1016/j.jplph.2007.02.011

[7] F. G. Fernandez, S. M. Brouder, J. J. Volenec, C. A. Beyrouty and R. Hoyum, "Soybean Shoot and Root Response to Localized Water and Potassium in a Split-Pot Study," Plant and Soil, Vol. 344, No. 1-2, 2011, pp. 197212. doi:10.1007/s11104-011-0740-Z

[8] C. Stritsis, B. Steingrobe, and N. Claassen, "Shoot Cadmium Concentration of Soil-Grown Plants as Related to Their Root Properties," Journal of Plant Nutrition and Soil Science, Vol. 175, No. 3, 2012, pp. 456-465. doi:10.1002/jpln.201100336
[9] Y. Wang, P. Marschner and F. S. Zhang, "Phosphorus Pools and Other Soil Properties in the Rhizosphere of Wheat and Legumes Growing in Three Soils in Monoculture or as a Mixture of Wheat and Legume," Plant and Soil, Vol. 354, No. 1-2, 2012, pp. 283-298. doi:10.1007/s11104-011-1065-7

[10] M. Iijima, Y. Kono, A. Yamauchi and J. R. Paedales, "Effects of Soil Compaction on the Development of Rice and Maize Root Systems," Environmental and Experimental Botany, Vol. 31, No. 3, 1991, pp. 333-342. doi:10.1016/0098-8472(91)90058-V

[11] A. G. Bengough, "Modelling Rooting Depth and Soil Strength in a Drying Soil Profile," Journal of Theoretical Biology, Vol. 186, No. 3, 1997, pp. 327-338. doi:10.1006/jtbi.1996.0367

[12] A. G. Bengough, M. F. Bransby, J. Hans, S. J. McKenna, T. J. Roberts and T. A. Valentine, "Root Responses to Soil Physical Conditions; Growth Dynamics from Field to Cell," Journal of Experimental Botany, Vol. 57, No. 2, 2006, pp. 437-447. doi:10.1093/jxb/erj003

[13] C. Becel, G. Vercambre and L. Pages, "Soil Penetration Resistance, a Suitable Soil Property to Account for Variations in Root Elongation and Branching," Plant and Soil, Vo. 353, No. 1-2, 2012, pp. 169-180. doi:10.1007/s11104-011-1020-7

[14] K. Yuge, M. Ito, Y. Nakano, M. Kuroda and T. Haraguchi, "Soil Moisture and Temperature Changes Affected by Isolated Plant Shadow," Journal of Agricultural Meteorology, Vol. 60, No. 5, 2005, pp. 717-720.

[15] K. Yuge, T. Haraguchi, Y. Nakano, M. Kuroda and M. Anan, "Quantification of Soil Surface Evaporation under Micro-Scale Advection in Drip-Irrigated Fields," Paddy Water Environment, Vol. 3, No. 1, 2005, pp. 5-12. doi:10.1007/s10333-004-0058-Z

[16] A. C. Chamberlain, "Transport of Gases to and from Surface with Bluff and Wave-Like Roughness Elements," Quarterly Journal of the Royal Meteorological Society, Vol. 94, No. 401, 1968, pp. 318-332. doi:10.1002/qj.49709440108 